\title{
ASSESSING READING TEXT IN ENGLISH TEXTBOOK FOR ELEVENTH GRADER PUBLISHED BY MINISTRY OF EDUCATION AND CULTURE
}

\author{
Rohib Adrianto Sangia \\ MAN 1 Ambon, rohib@ kemenag.go.id
}

\begin{abstract}
This research aims to answer the problems concerning the reading text material in English Textbook for Eleventh Grader published by Ministry of Education and Culture based on theory of good reading text (Nuttall, 2005). From three criteria proposed, this research focuses on the readability and suitability of reading text. There are two quantitative methods used in assessing readability, they are Miyazaki EFL Readability Formula and McAlpine ${ }^{\circledR}$ EFLAW Formula. In terms of assessing text suitability, the qualitative method is used by checking the target language covered by the reading text as the indicator of text suitability. Based on text readability, it is found out that overall reading texts Miyazaki EFL Readability score is $\mathbf{5 4 . 3 8}$ that can be interpreted as the reading text is in the level of fairly difficult and suitable to eleventh grader. While using McAlpine ${ }^{\circledR}$ EFLAW Formula, the readability score achieves 18.89 , meaning that the reading text in English textbook of eleventh grader is easy to understand. In terms of suitability, it shows that, from 22 items of target language that is expected to be covered by the text, there are only 12 items which contain the target language which means text suitability is about $54.54 \%$ from overall text.
\end{abstract}

Key Words: Reading Text, Readability, Suitability, EFL Readability formula.

\section{INTRODUCTION}

Teaching materials, for instance reading text, is an important part in the implementation of learning in school. Through teaching materials, for the teacher, it is easier to implement learning content and students are helped and easy to learn (Devetak \& Vogrinc, 2013: 3). Teaching materials can be written material or unwritten and used to help students in learning a certain subject. Teaching materials can be made in various shapes according to the needs and characteristics of teaching materials.

Textbooks are one of the essential teaching materials in teaching and learning activities. After all, many experts agree that they are the main resources 
in reading and endure a major instructional instrument in all grades except kindergarten (Bryce, 2013: 101). Besides that, it is useful for teachers who are not able or not ready to make their own teaching materials based on curriculum competency standard.

English Textbook for Eleventh Grader published by Ministry of Education and Culture is a compulsory textbooks published by the Education Ministry which is based on national curriculum 2013 to support education in Indonesia, in certain aspect, the availability of teaching materials. It is expected to avoid or to eliminate the gap between education in underdeveloped areas and the developed areas, in order to create learners who have mastery in science and technology. This textbook is considered as the primary textbook based on Education Ministry Regulation in succeeding the implementation of National Curriculum (Kementerian Pendidikan Nasional, 2008).

In reading program, every student frequently finds problems in understanding a long text. Once they notice the text with long sentences, words with long syllables, and many paragraphs, the reading process become uninteresting and it can cause the decrease of the student motivation in learning. It gives impact in students' comprehension of the text. In order to select the appropriate reading material to the students, Nuttall (2005) suggest at least three criteria in selecting the reading text. They are suitability, exploitability, and readability (see H. D. Brown, 2001: 314). Suitability means that the content of the text makes learners feel interested, enjoyed, challenged, and appropriate in achieve learning target. Exploitability gives the opportunity to achieving learning goals with the text that can be deep exploration to instructional task, techniques, and also can be integrated into other part of language skills. Readability implicates lexical and structural difficulty which encourages them without upset.

Manzo and Manzo (1990: 84) concern that generally, texts that have been written for Junior and Senior high school were converging to the content rather than for difficulty level. This comment has been inspiring of the textbook of junior and senior high school analysis in many places. 
Based on the problems referred earlier, the first problems about the difficulty of the text can be solved by assessing the text such as readability measurements. To determine the readability of a text or reading material can be measured by a variety of formulas (Schmidt \& Thomas, 2009: 73).

Readability is a term in the field of teaching reading which referring to text difficulty to find appropriate reading materials that students read (Mesmer, 2008: 7). Readability is often associated with the activities of whether the material is read by readers. From some views on legibility can be concluded that the legibility deciding factor is the difficulty of vocabulary as semantic variable and difficulty of sentence as syntactic variables.

In looking for a quick fix to match readers with reading material, Meade and Smith (1991: 154) list that readability formulas may be attracted for three reasons. Firstly, it is because their long position use in school settings. Secondly, their reputation is fit for systematic precision for organization text into suitable grade level groups. Thirdly, they perceived the notion of internal consistency within and between various formulas when determining reading levels.

Readability formulas are a formula that gives the figure as readability index. All readability formulas developed can predict whether a reading material is harder or easier to understand the reader when compared with other reading materials. The readability index can be used to predict the level of difficulty or ease-level reading material can be understood by the reader. The predictions can be used as a handle to determine the level of the reader. In addition, the prediction can be also used to determine or choose reading materials in accordance with a certain degree of reader comprehension (Burstein, 2009: 6).

Suitability of content is arguably the most important after interest. A text that the teacher cannot exploit is no use for teaching even if the students enjoy reading it. The purpose of the reading lesson definitely gives positive effect when the students are improving in their EFL knowledge. But this ought to be considered an incidental bonus where it is not the purpose of the reading lesson. In a reading lesson teachers are not setting out to teach language. Alternatively, if teachers are focusing to teach language, they do not get in situation in giving a 
reading lesson. The focus of interest in the reading lesson is neither language nor content, but the two together. It is useful in making the students learn that language is used for conveying content.

It should be realized the important of analysis of reading text in English Textbook for Eleventh Grader published by Ministry of Education and Culture since it is considered as crucial subject because they have just released in the early 2014. After all, this research is going to study the element of the text as reading teaching material from English Textbook for Eleventh Grader published by Ministry of Education and Culture. This certain judgment for this study hopefully can raise some consideration for the establishment in using this book for the teachers and learners.

The main research questions are aimed to answer the problems concerning the reading text material in English Textbook for Eleventh Grader published by Ministry of Education and Culture based on Nuttall's theory of good reading text. The research questions are formulated as the following:

1. How is readability of reading texts in English Textbook for Eleventh Grader published by Ministry of Education and Culture using Miyazaki EFL Readability Formula and McAlpine ${ }^{\circledR}$ EFLAW Formula?

2. How is suitability of reading texts in English Textbook for Eleventh Grader published by Ministry of Education and Culture fulfilled the competences that required in the curriculum?

The study is focusing on the evaluation of reading material in English Textbook for Eleventh Grader published by Ministry of Education and Culture. In aspect of investigating text difficulty, the method in measuring of the reading text is using Miyazaki Formula and McAlpine EFLAW® formula. The readability formula measurement is going to use method by using the developed feature which has provided by word processing program such as Microsoft ${ }^{\circledR}$ Word feature. 


\section{EFL Readability}

Mesmer (2008: 4) compiles the definition of readability as the term which refers to all the text features that effecting how one reads and understands a book. From the definitions, it is clear that readability scoping the relationship between the reader and the text, without considering the strategies or instruction which use in reading activities. The key purpose of readability existence is as a tool in matching the text and the reader.

In the application of readability, most of the formula is focusing to the text. After measuring the text, the result can be used in judging the best reader to a certain text. Further in following section is explanation about history, the factor in readability, readabilities formula, and its application in EFL.

Applying readability formulas outside the native English contexts in which the formulas were originally developed. Greenfield (2004) believes that the classic formula is unpractical to use, because it was requiring long-word and passagefrequency word counts in addition to parsing into function and non-function words. It left EFL teachers without an easy and reliable way to estimate a text's readability for their students. For such concerns, the research in formulating a new EFL readability formula was conducted. They are formula for Miyazaki Readability Index and McAlpine EFLAW® Index.

The Miyazaki study in readability also involved Japanese university students and checked the Flesch Reading Ease and Flesch-Kincaid formulas along Dale-Chall, etc. Then, after researched, tested and validated, the study gave an output result that for convenience Greenfield (2004: 11) and his colleagues socalled the Miyazaki EFL Readability Index.

Foreign learners of English, like all others, are troubled by long sentences. One would expect that they would be equally confounded by long words. Interestingly, that need not be the case. The McAlpine EFLAW® Index is different from other readability indexes, because of the emphasis on short words. Usually, for native English readers, long words cause problems, not short words. They are agitated by mini-words clusters (McAlpine, 2005).

\section{Reading Text Suitability}

158 | E-ISSN: 2527-8754 http:// journal.unesa.ac.id/index.php/Paramasastra 
Suitability, which Nuttall (2005: 30-31) defines as the facilitation of learning, is a key factor in selecting a reading material. Suitability refers to how the text can be used to develop the students' competence as readers. A text that cannot be exploited for teaching purposes has no use in the classroom. Just because it is in English does not mean that it can be useful. This indicates that the reading material helps the teacher to accomplish the objectives of the reading lesson or not. The content here was related to whether or not the texts provided were able to expand students' knowledge as well as to make students understand the target language.

With respect to suitability, the text content has to be developmentally, and linguistically, appropriate for improving the learners' comprehension strategies, and overcoming the vast amount of their reading deficiencies, because at the end, the basic learners deeply engaged in the meaning-making process of the selected text and therefore arrive successfully at thorough understanding of it.

\section{Textbooks in Curriculum 2013}

Curriculum is a product of education policy that has to change all the time. In reality, it is not tended to change but rather to make improvement. The continuous improvement which is conducted has purposed to accommodate the material which is considered important and up-to-date. The improvements are conducted as implementation of one of curriculum development principle that a curriculum should be dynamic and flexible, so it can be change anytime according to the need (Sukmadinata, 2007: 109). In order to fulfill the need of the society, the curriculum changes should be done gradually and systematically.

In curriculum 2013, textbook has significant role in teaching and learning process. By looking their importance, government makes the regulation about textbook procurement and spends a lot of funds in order to published and distribute the textbooks to the schools. The textbooks are used as a guidebook for teachers and students in learning activities in order to facilitate the students in mastering a specific competency. In addition, the textbook are published in two editions that are teacher's book and student's book. 
The textbooks is also used to carry out a number of activities in the learning process, where content is designed and equipped with several examples of an activity sheet that the students were able to learn something more relevant to the life they experienced. They are intended to make students more effectively in follow any learning process through which to observe the activities, ask, try reason, discuss and improve the ability of the students in good communication among class member and the teachers.

Student's book is used as a guide learning activities to help students master certain competencies. This book is also used to carry out activities in the learning process (activities-based learning) in which it is designed and equipped to examples of activity sheets for students to learn something relevant to the life they experienced. Student's book directed to students more active in participating in the learning process through the activities of observing, ask, try, reason, discuss and improve the ability to communicate either between friends or with the teacher. Teachers can develop or enrich the material and other activities in accordance with the learning objectives that have been set.

\section{Method}

Related to the theories in text readability, it performs the theories from both Greenfield (2003) in using Miyazaki EFL Readability Index and McAlpine EFLAW® from McAlpine (2005). From the theories, they are the tools to know and to evaluate the suitability the reading material. From the findings, it is expected to show a certain patterns of the readability results in order to make the harmony in learning process.

In investigating the research problems, at least it is conducted with descriptive quantitative as the research method. Descriptive research provides an answer to the questions of how something happened and who was involved, but not why something happened or why someone was involved (Ary, Jacobs, \& Sorensen, 2010: 454).

This study is called quantitative since it has a tendency to what Creswell (2012: 13) characterizes a quantitative study such as collecting numeric data from the study subjects. Moreover, another sign is the procedure of the research is 160 | E-ISSN: 2527-8754 http:// journal.unesa.ac.id/index.php/Paramasastra 
including the analyzing trends, comparing groups, or connecting variables using statistical analysis, and inferring results by comparing them with previous predictions and research.

In related to suitability of reading text, the descriptive analysis is conducted. Johnson and Christensen (2008: 66) confirm that in a descriptive qualitative research, the data collected are in the form of words or pictures, documented books, and the other notes rather than numbers. The data would be analyzed descriptively without any statistical calculation. Therefore, this study was designed in descriptive qualitative research because the object of the study was a documented book, then it belongs to a documentary analysis since the researcher analyzed the data or texts which were derived from the textbook, then those were described in depth.

The subjects are the reading texts which are that printed in English Textbook for Eleventh Grader published by Ministry of Education and Culture. A certain texts that are examined are the text that is really is used for reading topic according to syllabus. There are several things that are grabbed as the data in this study. By looking at Miyazaki EFL Readability formula, the data that are the formula input can be specified as numbers of letters, words, and sentences. The data for McAlpine EFLAW® are the number of words, number of mini-words, and number of sentences. Those are kind that can be defined as the linguistics elements of texts, which can be obtained from observing the texts.

Collecting Miyazaki EFL Readability input involves the counting letters, words, and sentences from the reading texts. With the purpose to gaining accuracy in using the software, it is necessary to type all the reading texts into form of Microsoft ${ }^{\circledR}$ Word data. When the texts are in form of word document, they can be converted and moved to the software analysis. Technique in collecting McAlpine EFLAW® input data involves the counting number of words, mini-words, and sentences from the reading texts. In order to have compromise and accuracy of the data, the counting is not only using manual method, but also it is used the Microsoft ${ }^{\circledR}$ Windows scripts. 
In collecting the data for suitability research, the researcher is using document observation technique. Not only reads over and over the reading materials in English Textbook, but also the researcher need to read over and over the learning goals of reading materials in Curriculum document particularly in the part of reading competence.

In selecting whether one is reading competences, it needs analysis of the curriculum document by observing and recognized them with viewing the syntax of competence sentence. Later on, the syntax that starts with certain operational or instruction words and containing the object that specify as the text, it definitely can be predicted has close connection with reading competences.

Analyzing the data is started with measuring the readability of each text based on the Miyazaki EFL Readability Formula.

$$
E F L \text { Difficulty }=164.935-\left(18.792 \times \frac{\text { Letters }}{\text { Words }}\right)-\left(1.916 \times \frac{\text { Words }}{\text { Sentences }}\right)
$$

After that, it continues with describing and giving further explanation related to the readability. Later on, it is determining the index of each reading texts by comparing the results of the scores to the other criteria as shown in the readability index.

Analyzing the data is started with measuring the readability of each text based on the McAlpine EFLAW® Formula.

McAlpine EFLAW ${ }$ Score $=\frac{(\text { Number of } \text { Words }+ \text { Number of Miniwords) }}{\text { Number of Sentences }}$

After that, it continues with describing and giving further explanation related to the readability. Later on, it is determining the index of each reading texts by comparing the results of the scores to the other criteria as shown in the readability index.

Basically, suitability concerns to the content of the reading text. It means that more the target language based on the reading competence in the text, the increasing validity of the reading material to the curriculum demands. In order to capture the data, and analyze them, it is using some kind checklist that contains both text columns and target language columns.

162 | E-ISSN: 2527-8754 http:// journal.unesa.ac.id/index.php/Paramasastra 


\section{DISCUSSION}

\section{Miyazaki EFL Readability}

Based on the texts result (see Table 1), they can be summarized as the longest text is Text 5 because it has the most numbers of letters and words. And the shortest text is hold by Text 10 since it has the fewest letters and words numbers. Then, for the all text readability score based on Miyazaki Readability formula, Text 10 is considered is the easiest text from the textbook with score 90.21 and Text 09 is projected as the hardest text to be read with readability score 30.53 .

Table 1 Miyazaki Results

\begin{tabular}{|c|c|c|l|l|c|}
\hline No & $\begin{array}{c}\text { Text } \\
\text { Code }\end{array}$ & $\begin{array}{c}\text { Readability } \\
\text { Score }\end{array}$ & Style Description & $\begin{array}{c}\text { Estimated } \\
\text { Reading } \\
\text { Grade }\end{array}$ & Quality \\
\hline \hline 1. & Text 01 & 67.01 & Standard & $8^{\text {th }}$ and $9^{\text {th }}$ & Easier \\
\hline 2. & Text 02 & 42.95 & Difficult & College & Harder \\
\hline 3. & Text 03 & 51.04 & Fairly Difficult & $10^{\text {th }}$ to $12^{\text {th }}$ & Match \\
\hline 4. & Text 04 & 64.09 & Standard & $8^{\text {th }}$ and $9^{\text {th }}$ & Easier \\
\hline 5. & Text 05 & 63.20 & Standard & $8^{\text {th }}$ and $9^{\text {th }}$ & Easier \\
\hline 6. & Text 06 & 30.68 & Difficult & College & Harder \\
\hline 7. & Text 07 & 40.32 & Difficult & College & Harder \\
\hline 8. & Text 08 & 65.60 & Standard & $8^{\text {th }}$ and $9^{\text {th }}$ & Easier \\
\hline 9. & Text 09 & 30.53 & Difficult & College & Harder \\
\hline 10. & Text 10 & 90.21 & Very Easy & $5^{\text {th }}$ grade & Easier \\
\hline 11. & Text 11 & 37.95 & Difficult & College & Harder \\
\hline \hline \multicolumn{7}{|c|}{ Overall } & $\mathbf{5 4 . 3 8}$ & Fairly Difficult & $10^{\text {th }}$ to $12^{\text {th }}$ & Match \\
\hline \hline
\end{tabular}

In the first volume of the textbook, it finds that the overall readability score from text 01 to Text 05 is 60.38 . It means that the first volume is easier to be read by the eleventh grader students. In the second volume, the finding shows that the accumulation of the readability variables from Text 06 to Text 11, makes the second volume overall readability score 47.68. This is far from the previous volume results. It makes the second volume is consistently harder than the first volume. After gaining all readability score from Text 01 to Text 11 , finally the 
readability score of all reading text from the textbook based on Miyazaki Readability formula is 54.38 .

There is oscillation of readability score by looking the reading texts one by one (see Figure 4.1). The result shows that there is wide range of readability score for each text. The range of the readability score is very easy for text 09 to difficult for text 10 . The contrast is revealed when all of readability score of reading texts in English textbook for eleventh grader published by Ministry of Education and Culture, counted on average, the results shows that the quality of reading text based on theory by Miyazaki EFL Readability Index, the reading text is suitable for eleventh grader.

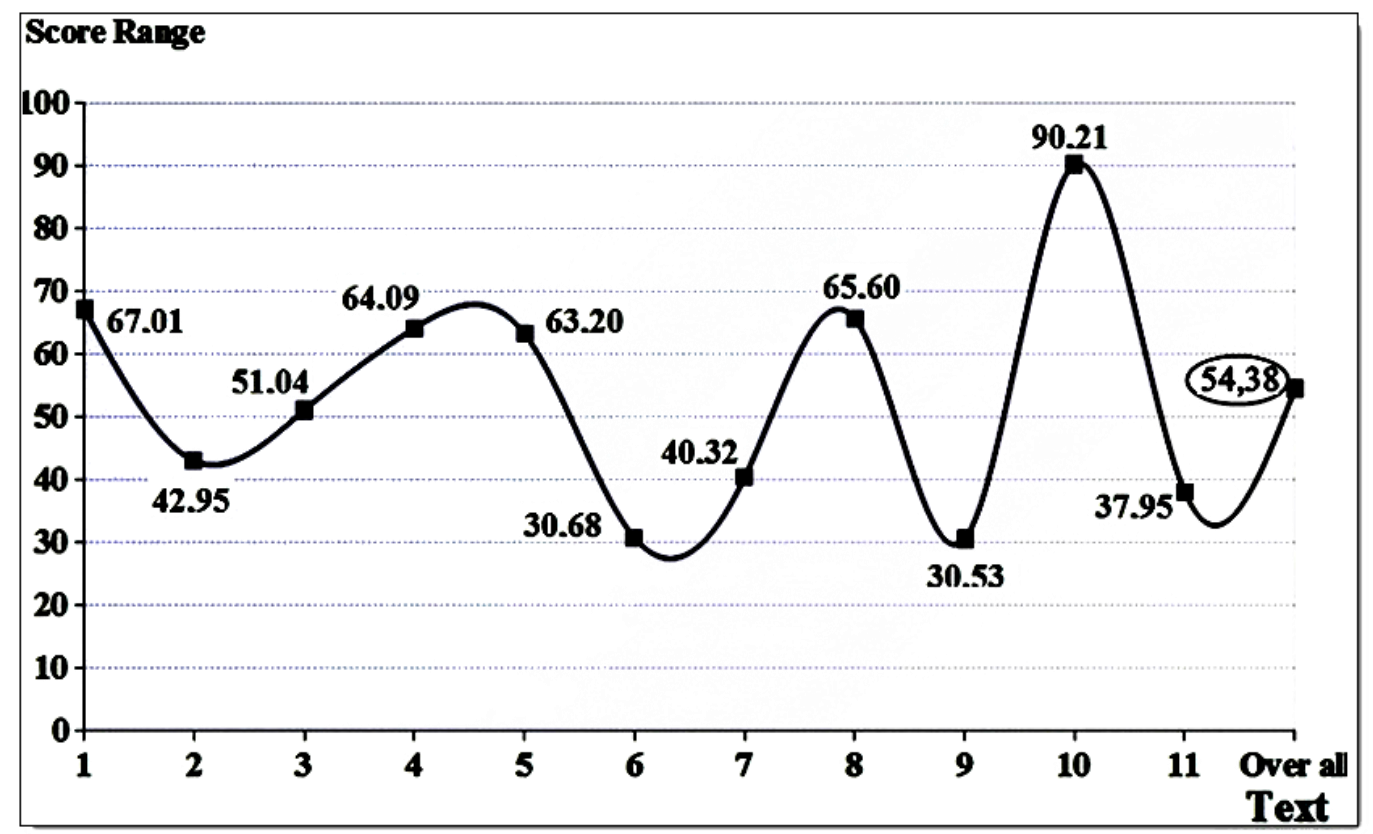

Figure 1 Miyazaki Readability Score Sequences

\section{McAlpine® EFLAW Readability}

Table 2 McAlpine ${ }^{\circ}$ Results 


\begin{tabular}{|c|c|c|c|}
\hline No & Text Code & Readability Score & Description \\
\hline 1. & Text 01 & 21.11 & Quite easy to Understand \\
\hline 2. & Text 02 & 24.20 & Quite easy to Understand \\
\hline 3. & Text 03 & 22.24 & Quite easy to Understand \\
\hline 4. & Text 04 & 11.77 & Very easy to Understand \\
\hline 5. & Text 05 & 18.77 & Very easy to Understand \\
\hline 6. & Text 06 & 24.47 & Quite easy to Understand \\
\hline 7. & Text 07 & 21.49 & Quite easy to Understand \\
\hline 8. & Text 08 & 15.65 & Very easy to Understand \\
\hline 9. & Text 09 & 27.68 & A Little Difficult \\
\hline 10. & Text 10 & 9.32 & Very easy to Understand \\
\hline 11. & Text 11 & 26.88 & A Little Difficult \\
\hline \hline \multicolumn{2}{|c|}{ Overall } & $\mathbf{1 8 . 8 9}$ & Very easy to Understand \\
\hline
\end{tabular}

The quality of the text is described in three ways. The first is very easy to understand when the readability score is among score $0-20$. The second is when the readability score between 21 and 25, it is interpreted as quite easy to understand. And the third place which is when the score is taking place between 26 and 29 that it is a little difficult. The findings show that there are four texts are considered as very easy to be understood, then there are five texts is interpreted as quite easy to be understood, finally the rest couple texts are measured as a little difficult to be understood.

In the first volume of the textbook, it finds that the overall readability score from text 01 to Text 05 is 17.87 that makes it is very easy to be understood by the eleventh grader students. In the second volume, the finding shows that the accumulation of the readability variables from Text 06 to Text 11 , makes the second volume overall readability score 20.16. This is increasing from the previous volume results. It makes the second volume is consistently harder than the first volume. As the conclusion, by measuring all the texts at once, it is reflected that overall text is very easy to be understand (see Table 2) 


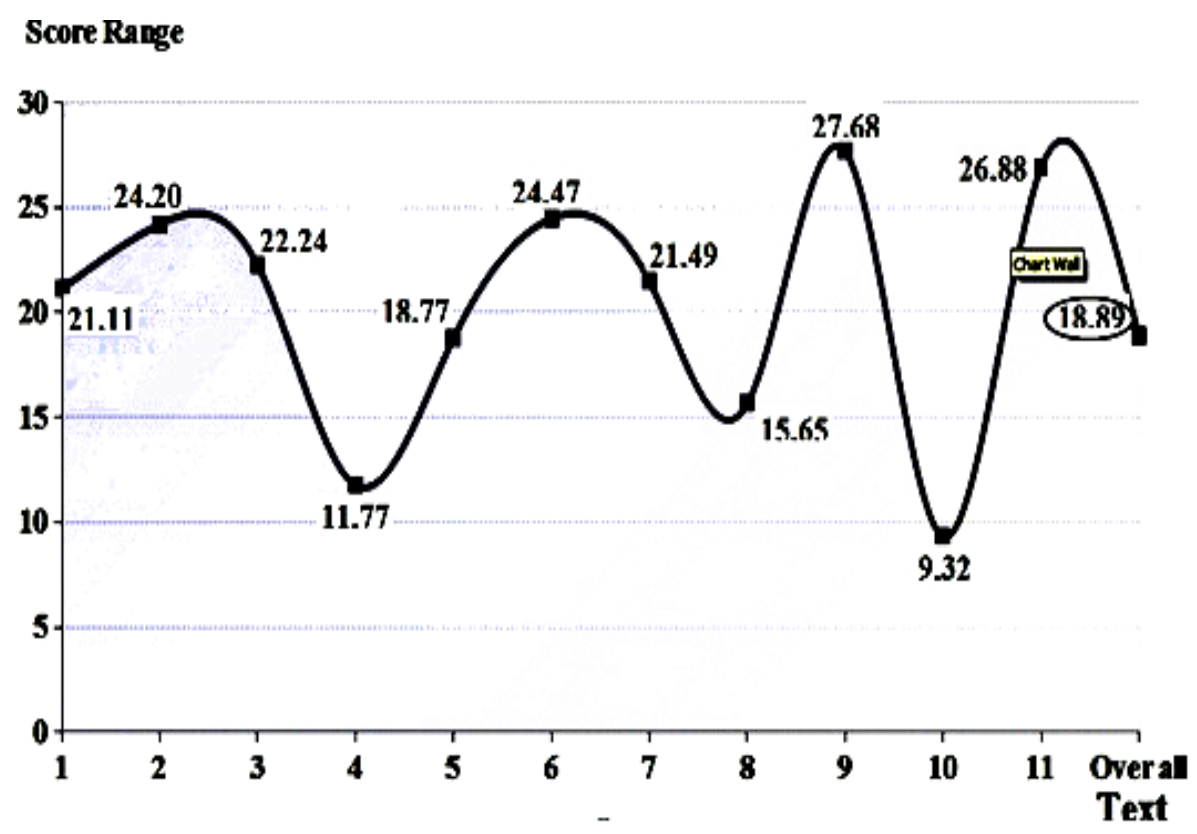

Figure 2 McAlpine ${ }^{\circledR}$ EFLAW Score Sequences

There is oscillation of readability score by looking the reading texts one by one (see figure 2). The result shows that there is wide range of readability score for each text. The range of the readability score are very easy to understand for text 10 to a little difficult for text 09 .

\section{Results Comparison}

Table 3 describes the results between two readability score for each text in order. The columns mainly describe the readability score. The readability score shows the quality of the text based on readability formula. Trend shows the dynamic condition of readability score by comparing it with the previous text's readability score. 
Table 3 Readability Score Comparison

\begin{tabular}{|c|c|c|l|c|l|}
\hline No & Text & $\begin{array}{c}\text { Miyazaki } \\
\text { Readability } \\
\text { Score }\end{array}$ & Trend & $\begin{array}{c}\text { McAlpine® } \\
\text { EFLAW } \\
\text { Score }\end{array}$ & Trend \\
\hline \hline 1. & Text 01 & 67.01 & - & 21.11 & - \\
\hline 2. & Text 02 & 42.95 & Harder & 24.20 & Harder \\
\hline 3. & Text 03 & 51.04 & Easier & 22.24 & Easier \\
\hline 4. & Text 04 & 64.09 & Easier & 11.77 & Easier \\
\hline 5. & Text 05 & 63.20 & Harder & 18.77 & Harder \\
\hline 6. & Text 06 & 30.68 & Harder & 24.47 & Harder \\
\hline 7. & Text 07 & 40.32 & Easier & 21.49 & Easier \\
\hline 8. & Text 08 & 65.60 & Easier & 15.65 & Easier \\
\hline 9. & Text 09 & 30.53 & Harder & 27.68 & Harder \\
\hline 10. & Text 10 & 90.21 & Easier & 9.32 & Harder \\
\hline 11. & Text 11 & 37.95 & Harder & 26.88 & Harder \\
\hline \hline \multicolumn{7}{|c|}{ Overall } & 18.89 \\
\hline \hline
\end{tabular}

Most of the results based on two readability formulas give the similar trend. Since the trend of the score is in parallel condition, the results of both methods consistently and convincingly contribute the same results in determining the hardest and the easiest text.

Figure 3 gives the image of the trend about the score chronologically for both methods. The trend of the methods displays similarity that gives the same waves or oscillations, as well as the lowest and the highest scores. This trend has been predicted if the formula is analyzed in details. Basically, both of the formula are using the basic variables in common readability formulas. The base variables are number of text elements that are words and sentences. The modification makes them different since the adding of another variable which is considered by their inventor. Miyazaki formula is emphasizing in number of letters as the extended variable meanwhile McAlpine ${ }^{\circledR}$ prefers to mini-words with the arguments that number of miniwords significantly affecting the difficulty of a text.

The other results of the similar trend between those two formulas are the similarity of the hardest text and the easiest text from the textbook. It is found that 
text 09 is measured as the hardest text, and text 10 is reflected as the easiest text from all the text in the textbook.

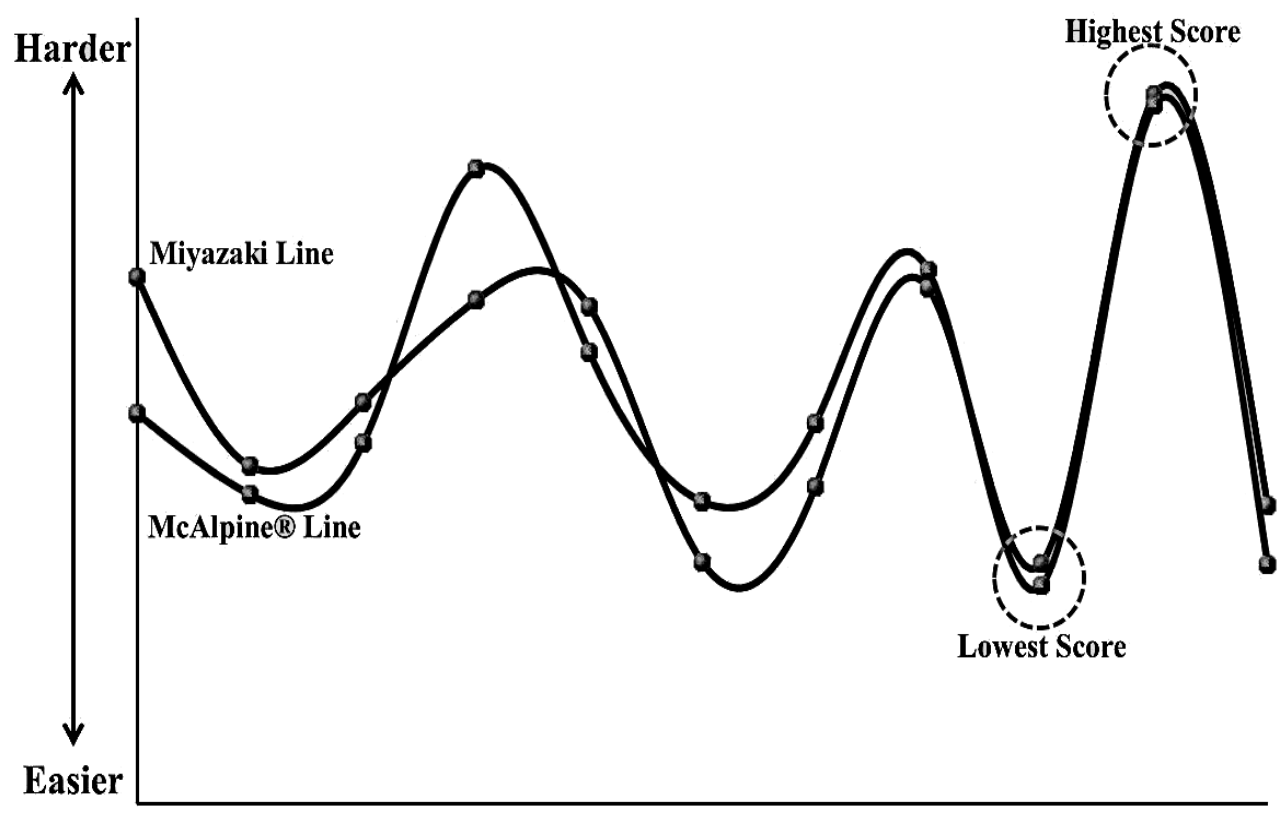

Text 01

Text 11

Figure 3 Readability Score Trend

\section{Suitability of Reading Text}

It is believe that curriculum is made by using taxonomy in order to make learning sequences which useful for both teachers and students for curriculum 2013, government states that there are 4 basic taxonomies in developing curriculum to be implemented in schools. They are spiritual aspect, social aspect, knowledge aspect and the skills aspect.

In analyzing the core competence and bas competence, this study limits the range of taxonomies only covers for knowledge aspect and skill aspect which covering base competence number 3 and base competence number 4 . From both types of base competences, it is extracted the proper material or target language that should be in the reading text so that can be material that can help the student in achieving learning goals.

A good text need to present the target language as the indicator that a text can be exploited based on the learning objective. Finding shows that all the texts 
cannot accommodate the require target language that should be presented. From 22 items of target language, there are 12 items that are not covered by the texts that can be exploited by teachers or students in helping those achieving learning goals. The domination of target language is taking by social function, text structure, and language feature from the text itself. Finally, from the results, it can be calculated that the suitability of overall reading texts is projected at $54.54 \%$.

\section{CONCLUSIONS}

There are several results based on the readability and the suitability of the reading text. In terms of readability, two methods have been applied. The first method, by using Miyazaki EFL Readability presents that the overall reading texts readability score is 54.38 and that can be interpreted as the reading text in the level of fairly difficult and suitable to eleventh grader. By using McAlpine ${ }^{\circledR}$ EFLAW Formula, the readability score achieves 18.89 with the meaning that the reading texts in English textbook for eleventh grader is very easy to understand.

Both of the volumes show consistency that the first volume is more readable than the second volume both in terms of Miyazaki Readability method and McAlpine ${ }^{\circledR}$ EFLAW Readability. Moreover, in the process of counting the readability score, both readability methods consistently and convincingly confirmed that Text 09 is the hardest text to be digested by the students and Text 10 is the easiest to understand.

In conducting suitability research, the target language has been checked against the curriculum. It gives results that, from 22 items of target language that are expected to be covered by the text, there are only 12 items which contain the proper target language. It means that the result of text suitability is about $54.54 \%$ from overall text.

The results give the impressions that not all of target languages are found in reading materials. It is because that reading text is not the only component of a good textbook. By looking on the items of the checklist, the reading material has fulfilled the reading skills based on the language objectives. The rest of text 
suitability is to be found in other parts of the textbook such as assessment sheets as well as activity sheets.

\section{REFERENCES}

Ary, Donald, Jacobs, Lucy Cheser, \& Sorensen, Chris. 2010. Introduction to Research in Education. Belmont: Wadsworth.

Brown. 1998. An EFL Readability Index. JALT Journal, 20 (2), 7-36.

Bryce, Nadine. 2013. Textual Features and Language Demands of Primary Grade

Science Textbooks: The Call for More Informational Texts in Primary Grades. In M. S. Khine (Ed.), Critical Analysis of Science Textbooks (pp. 101-120). London: Springer.

Burstein, Jill. 2009. Opportunities for Natural Language Processing Research in Education. In A. Gelbukh (Ed.), Computational Linguistics and Intelligent Text Processing (pp. 6-27). Mexico City: Springer.

Creswell, John W. 2012. Educational Research : Planning, Conducting, and Evaluating Quantitative and Qualitative Research. Boston: Pearson.

Devetak, Iztok, \& Vogrinc, Janez. 2013. The Criteria for Evaluating the Quality of the Science Textbooks In M. S. Khine (Ed.), Critical Analysis of Science Textbooks (pp. 3-15). London: Springer.

Greenfield, Jerry. 2003. The Miyazaki EFL Readability Index. Comparative Culture, 9, 41-49.

Greenfield, Jerry. 2004. Readability Formulas for EFL. JALT Journal, 26(1), 5-24 Johnson, Burke, \& Christensen, Larry B. 2008. Educational Research : Quantitative, Qualitative, and Mixed Approaches. Los Angeles: Sage Publications.

Kementerian Pendidikan Nasional. 2008. Peraturan Menteri Pendidikan Nasional Republik Indonesia Nomor 2 Tahun 2008.

Manzo, Anthony V., \& Manzo, Ula Casale. 1990. Content Area Reading : a Heuristic Approach. Columbus: Merrill Pub. Co.

McAlpine, Rachel. 2005. Global English for Global Business. Wellington: CC Press. 
Rohib, Assessing Reading ...(hal 154-171)

Meade, Cathy D, \& Smith, Cyrus F. 1991. Readability Formulas: Cautions and Criteria. Patient Education and Counseling, 17 (2), 153-158.

Mesmer, Heidi Anne E. 2008. Tools for Matching Readers to Texts : ResearchBased Practices. New York: Guilford Press.

Nuttall, Christine. 2005. Teaching Reading Skills in a Foreign Language(3rd ed.). Oxford: Macmillan.

Schmidt, Renita Revland, \& Thomas, Paul Lee. 2009. 21st Century Literacy: If We are Scripted, are We Literate? (Vol. 5). London: Springer Science \& Business Media.

Sukmadinata, Nana Syaodih. 2007. Kurikulum dan Pembelajaran. In FIP-UPI (Ed.), Ilmu dan Aplikasi Pendidikan Bagian 2 (pp. 97-132). Bandung: PT Imtima Grasindo. 